\title{
Mortalidade perinatal de cordeiros no semi-árido da Paraíba $^{1}$
}

\author{
Janduí Escarião da Nóbrega $\mathrm{Jr}^{2}$, Franklin Riet-Correa ${ }^{3 *}$, Rossana S. Nóbrega ${ }^{4}$ \\ Josemar M. de Medeiros ${ }^{2}$, Jackson S. de Vasconcelos ${ }^{4}$, Sara Vilar D. Simões ${ }^{3}$ e \\ Ivon M. Tabosa ${ }^{3}$
}

\begin{abstract}
Nóbrega JrJ.E., Riet-Correa F., Nóbrega R.S., Medeiros J.M., Vasconcelos J.S., Simões S.V.D. \& Tabosa I.M. 2005. [Perinatal mortality of lambs in the semi-arid region of Paraíba, Brazil.] Mortalidade perinatal de cordeiros no semi-árido da Paraíba. Pesquisa Veterinária Brasileira 25(3):171-178. Centro de Saúde e Tecnologia Rural, UFCG, Campus de Patos, 58700-000 Patos, PB, Brazil.E-mail: riet@cstr.ufcg.edu.br

The causes of perinatal lamb mortality were studied, from March 2002 to October 2004, on 27 farms in the semiarid region of Paraíba, northeastern Brazil. In 90 lambs necropsied the following frequency of different causes of death was found: neonatal infections (41.1\%), malformations $(23.3 \%)$, dystocia $(10 \%)$, starvation/hypothermia $(10 \%)$, abortion $(4.4 \%)$, and predation $(2.2 \%)$. Regarding the time of death, $4.4 \%$ of the lambs died before parturition, $10 \%$ during parturition, $30 \%$ on the first day after parturition, $20 \%$ between the second and the third day, and $35.6 \%$ between the 4 th and the 28th day after parturition. The assistance during parturition, umbilical disinfection of the neonates, colostrum ingestion between 2 and 6 hours after parturition, and keeping the ewes in healthy environmental conditions during and after parturition could improve lamb surviving. The high frequency of malformations in different breeds suggests that malformations are due to a toxic plant. The main defects were permanent flexure of the front legs, brachygnathia, cleft palate, and other head malformations. In a recent report the authors demonstrated the teratogenic effects of Mimosa tenuiflora, a very common plant in the semiarid region, which is probably the cause of those malformations. Lambs which died due to starvation/hypothermia and had low birth weight $(1.37 \pm 0.70 \mathrm{~kg})$, suggesting that a better nutrition of the ewe during the last trimester of gestation is a way to control this cause of lamb mortality. Considering that in the northeastern region, in most farms, the rams stay with the ewes during the whole year, the adoption of a breeding season would help to control the different causes of perinatal lamb mortality.
\end{abstract}

INDEX TERMS: Lamb mortality, newborn lambs, sheep production, perinatal mortality.

RESUMO.- As causas de mortalidade perinatal em ovinos foram estudadas de março de 2002 a outubro 2004 em 27 fazendas da região semi-árida da Paraíba. De 90 cordeiros necropsiados, $41,1 \%$ morreram de infecções neonatais, $23,3 \%$ por malformações, $10 \%$ por inanição/hipotermia, $10 \%$ por distocia, $2,2 \%$ por predação e 4,4\% foram abortos sem causa identificada. Em relação ao momento da morte, $4,4 \%$ dos cordeiros morreram antes do parto, $10 \%$ durante o parto, $30 \%$ no primeiro dia de vida, $20 \%$

\footnotetext{
${ }^{1}$ Recebido em 9 de março de 2005.

Aceito para publicação em 14 de abril de 2005.

Parte da dissertação de mestrado do primeiro autor no Programa de Pós-Graduação em Medicina Veterinária em Pequenos Ruminantes, UFCG/ CSTR, Campus de Patos, Paraíba.
}

entre o $2^{\circ}$ e $5^{\circ}$ dia e $35,6 \%$ entre o $4^{\circ}$ e $28^{\circ}$ dia após o parto. A assistência das ovelhas durante o parto, a desinfecção do umbigo dos cordeiros, a ingestão de colostro 2 a 6 horas após o parto, e a manutenção das ovelhas em locais adequados durante e após o parto contribuiriam para diminuir as mortes perinatais por distocia e infecções neonatais. A alta freqüência de malformações, em diferentes raças, sugere que esses defeitos sejam causados por uma planta tóxica. Os principais defeitos

\footnotetext{
${ }^{2}$ Programa de Pós-Graduação em Medicina Veterinária em Pequenos Ruminantes, UFCG/CSTR, Campus de Patos, 58700-000 Patos, Paraíba.

${ }^{3}$ Centro de Saúde e Tecnologia Rural, UFCG, Campus de Patos, 58700-000 Patos, Paraíba. "Autor para correspondência. E-mail: riet@cstr.ufcg.edu.br

${ }^{4}$ Aluno de Graduação do Curso de Medicina Veterinária, UFCG/CSTR, bolsista do PIBIC.
} 
observados foram a flexão permanente dos membros anteriores, braquignatismo, fenda palatina e outras alterações dos ossos da cabeça. Recentemente foi demonstrado o efeito teratogênico de Mimosa tenuiflora ("jurema-preta"), uma planta muito comum na região semi-árida, nas áreas de caatinga, que aparentemente é responsável pelas malformações. Os cordeiros mortos por inanição/hipotermia tiveram baixo peso ao nascimento $(1,37 \pm 0,7 \mathrm{~kg})$ o que sugere que a principal causa dessas mortes é a deficiente nutrição da mãe durante o último terço da gestação. Considerando-se que na região nordeste, na maioria das fazendas, os carneiros permanecem com as ovelhas durante todo $\mathrm{o}$ ano, a adoção de uma estação de monta definida contribuiria para a diminuição da mortalidade perinatal.

INDEX TERMS: Mortalidade perinatal, cordeiros, ovinocultura, mortalidade de cordeiros.

\section{INTRODUÇÃO}

Define-se como mortalidade perinatal de ovinos as mortes que ocorrem entre os 60 dias de gestação e os 28 dias após o parto. Essas mortes podem ocorrer antes do parto (abortos), durante $o$ parto ou após o parto (Riet-Correa \& Méndez 2001).

Entre as causas de mortalidade perinatal encontram-se: os abortos infecciosos, que podem ser causados por Toxoplasma gondii, Salmonella abortus ovis, Listeria monocytogenes, Brucella ovis, Campylobacter fetus var. intestinalis ou Clamydia psittaci; o complexo inanição/hipotermia; as distocias; as infecções neonatais; as malformações; e a predação por cães e animais silvestres (Radostits et al. 2000, Riet-Correa \& Méndez 2001). Entre essas causas, uma das principais é o denominado complexo inanição/ hipotermia/ hipoglicemia/ exposição (Radostits et al. 2000), denominado, também, como complexo inanição/exposição (RietCorrea \& Méndez 2001) e que neste trabalho definimos como complexo inanição/hipotermia. Este complexo ocorre quando o cordeiro não tem reservas energéticas suficientes para manter sua temperatura corporal; dois fatores são determinantes para a ocorrência da morte: condições climáticas adversas; e baixo peso ao nascimento, que acarreta maior perda de calor e menores reservas energéticas (Riet-Correa \& Méndez 2001).

Em regiões de clima temperado, a mortalidade perinatal é uma das principais causas de perdas econômicas para a ovinocultura. Na Austrália, Nova Zelândia e Inglaterra essas perdas variam entre $2 \%$ e 21\% (Hartley \& Boyes 1964, McFarlane 1965, Stamp 1967). No Uruguai $17 \%$ a $32 \%$ dos cordeiros nascidos anualmente morrem no período perinatal (Mari \& McCosker 1975).

Em regiões semi-áridas do mundo, a mortalidade perinatal de cordeiros é ainda maior que em regiões temperadas, variando de 46,3 a $51,5 \%$ na Etiópia, onde o complexo inanição/ hipotermia é a causa mais prevalente (Bekele et al. 1992), de 17,6 a 31,3\% no Marrocos, sendo também a inanição/hipotermia a principal causa (Chaarani et al. 1991), e de 33,5\% em Ghana (Turkson 2003).

No Brasil, no Rio Grande do Sul, estima-se que morram 15\% a $40 \%$ dos cordeiros nascidos (Riet-Correa \& Méndez 2001). Nesse Estado, a principal causa de mortalidade é o complexo inanição/ hipotermia, responsável por $56 \%$ a $78 \%$ das mortes, seguido das distocias $(8,6 \%$ a $16,7 \%)$. A predação primária, as infecções neonatais, os abortos e as malformações congênitas foram pouco freqüentes, menos de 5\% para cada uma delas (Méndez et al. 1982, Oliveira \& Barros 1982, Hancock et al. 1996).

No semi-árido do Brasil existem poucas referências sobre as taxas de mortalidade em ovinos. Lobo (2003) menciona uma mortalidade anterior a desmama de $28,79 \% \pm 16,02$, com um mínimo de $15,18 \%$ e um máximo de $46,45 \%$. Num núcleo de melhoramento pertencente a Embrapa/CPAMN no estado do Piauí a mortalidade de cordeiros foi de $15,18 \%$; ocorrendo maior taxa de mortalidade entre os cordeiros nascidos de partos gemelares $(24,74 \%)$ do que nos cordeiros de parto simples $(12,13 \%)$ (Girão et al. 1998). Outros trabalhos realizados, também, em sistemas de produção melhorados mencionam mortalidades de $9,52 \%$ a $18,2 \%$ em diversas raças deslanadas (Lima 1985). Não há trabalhos sobre a importância da mortalidade perinatal em ovinos criados em forma extensiva, com baixa tecnologia, na região Nordeste; no entanto, fazendeiros mencionam percentuais de mortalidade superiores a $50 \%$. Também não há trabalhos sobre as principais causas de mortalidade perinatal.

Para diminuir as altas taxas de mortalidade de cordeiros e aumentar a rentabilidade da ovinocultura é necessário, inicialmente, determinar as causas dessa mortalidade. O objetivo deste trabalho é determinar as causas de mortalidade perinatal em ovinos no semi-árido da Paraíba.

\section{MATERIAL E MÉTODOS}

O trabalho foi realizado em um total de 27 fazendas no estado da Paraíba, sendo 24 localizadas na região do Sertão e 3 no Cariri, entre março de 2002 e outubro de 2004. Em cada propriedade selecionada fazia-se a coleta dos cordeiros mortos durante o período perinatal. Para isso, as fazendas eram visitadas periodicamente durante a época de parição ou quando o proprietário informava por telefone que havia animais mortos para serem coletados. Na impossibilidade de coleta diária foram deixados congeladores em algumas propriedades, beneficiando mais de uma propriedade com um único congelador. Os cordeiros eram acondicionados individualmente em sacos plásticos, com identificação da propriedade e enviados para o Hospital Veterinário da Universidade Federal de Campina Grande, Campus de Patos, onde eram necropsiados após o descongelamento.

Foram realizadas 90 necropsias, utilizando-se o método descrito inicialmente por McFarlane (1965) com algumas modificações sugeridas por Méndez et al. (1982). Para determinar se o cordeiro morreu antes, durante ou após o parto foram considerados sinais de viabilidade e sinais de sobrevivência. Os sinais de viabilidade, que indicavam que o animal estava vivo no momento do parto foram: aeração pulmonar; presença de coágulos nos vasos umbilicais; e edemas subcutâneos localizados. Os sinais de sobrevivência, que indicavam que o cordeiro viveu algum tempo após o parto foram: evidência de ter caminhado ou se alimentado, ausência de mecônio no intestino e aparecimento dos incisivos. Seguindo esses conceitos, o momento da morte foi classificado em antes do parto, durante o parto e após o parto. (A) Antes do parto: animais sem nenhum sinal de viabilidade, geralmente com líquido soro-hemorrágico no tecido subcutâneo e nas cavidades abdominal e torácica e com sinais de autólise; (B) Durante o parto: animais sem coágulos nas artérias umbilicais, com aeração pulmonar total ou parcial, com edemas em algumas partes do corpo, podendo apresentar hemorragias das meninges ou cavidade abdominal. Esses animais apresentavam evidências de ter caminhado ou se alimentado; (C) Após o parto: animais com coágulos nos vasos umbilicais e aeração pulmonar 
podendo apresentar, ou não, sinais de sobrevivência. Após o parto foram computados três períodos: $\left(\mathrm{C}_{1}\right)$ Pós-parto imediato (até 24 horas): animais bem hidratados que geralmente não caminharam e não se alimentaram, com umbigo úmido, presença de mecônio e os incisivos não apareceram; $\left(\mathrm{C}_{2}\right)$ Pós-parto dilatado (24-72 horas): animais que caminharam, se alimentaram ou não, com presença de mecônio no intestino e com os incisivos começando a aparecer na gengiva, podendo também estar desidratados; $\left(\mathrm{C}_{3}\right)$ Pós-parto tardio (3-28 dias): cordeiros com os mesmos sinais da categoria anterior, embora com evidências de terem sobrevivido mais de 3 dias, indicado pela presença de vários incisivos na gengiva e ausência de mecônio no intestino.

As causas de morte consideradas foram as seguintes:

(1) Abortos: cordeiros mortos antes do parto.

(2) Complexo inanição/hipotermia: cordeiros que caminharam, mas não se alimentaram. Apresentavam-se desidratados, com pouca reserva de gordura, com fígado escuro de consistência aumentada, bexiga cheia de urina e adrenais aumentadas de tamanho e hemorrágicas.

(3) Distocia: animais com edemas subcutâneos claros localizados na cabeça, pescoço, períneo e/ou membros, podendo apresentar autólise do córtex renal, com hemorragias nas meninges e/ou cavidade abdominal. Em cordeiros que apresentavam malformações como fator desencadeante de distocias, foi considerada como causa de morte a malformação.

(4) Infeç̧ões neonatais: cordeiros com lesões tais como: onfaloflebite, artrite, enterite, meningite, pneumonia, abscessos, eimeriose e outras infecções pós-natais.

(5) Malformação congênita: animais com defeitos congênitos considerados letais.

(6) Predação: animais com hemorragias ou outras lesões traumáticas na pele, tecido subcutâneo, músculos e ossos.

Quadro 1. Causas de mortalidade perinatal em ovinos necropsiados nos anos de 2002 e 2004 no semi-árido paraibano

\begin{tabular}{lccc}
\hline \multicolumn{1}{c}{ Diagnóstico } & Total & $\%$ & $\begin{array}{c}\text { Peso }(\mathrm{kg}) \\
\text { (Media } \pm \mathrm{s})\end{array}$ \\
\hline Aborto & 4 & 4,44 & $1,37 \pm 0,70$ \\
Complexo inanição/hipotermia. & 9 & 10,00 & $2,37 \pm 0,90$ \\
Distocias & 9 & 10,00 & $3,06 \pm 1,43$ \\
Infecção neonatal & 37 & 41,11 & $2,81 \pm 1,02$ \\
Malformação & 21 & 23,34 & $2,59 \pm 0,76$ \\
Predação & 2 & 2,22 & $3,30 \pm 0,42$ \\
Sem diagnóstico & 8 & 8,89 & $3,06 \pm 0,98$ \\
Total & 90 & 100,00 & $2,72 \pm 1,00$ \\
\hline
\end{tabular}

a Um caso de predação primária por cães e outro por ave de rapina, não sendo possível determinar, neste último, se a predação foi primária ou secundária.

Quadro 2. Mortalidade perinatal em ovinos. Momento da morte em cordeiros necropsiados nos anos de 2002 e 2004 no semi-árido paraibano

\begin{tabular}{lc}
\hline Momento de morte & № (\%) \\
\hline Antes do parto & $4(4,44 \%)$ \\
Durante o parto & $9(10 \%)$ \\
Pós-parto imediato & $27(30 \%)$ \\
Pós-parto dilatado & $18(20 \%)$ \\
Pós-parto tardio & $32(35,56 \%)$ \\
Total & $90(100 \%)$
\end{tabular}

Em todos os casos de aborto e em outros casos nos quais o diagnóstico não foi realizado pela necropsia, cortes de vários órgãos e tecidos das cavidades abdominal e torácica e sistema nervoso central foram fixados em formol neutro a $10 \%$ para estudo histológico. Esses materiais eram incluídos em parafina, cortados a 6 ìm e corados por hematoxilina-eosina.

Em 12 casos foram enviados fragmentos de fígado, pulmão, rim, coração ou outros órgãos que apresentavam lesões para cultivo e isolamento bacteriológico em ágar sangue e ágar McKonkey. Após a semeadura os cultivos foram incubados em aerobiose ou microaerofilia a $37^{\circ} \mathrm{C}$ por $24-48$ horas. Nos casos de aborto foram realizados cultivos do conteúdo do abomaso e, em um caso, da placenta.

Para o diagnóstico das malformações ósseas foi realizada a técnica de maceração assistida, submergindo a carcaça sem a pele e sem as vísceras em água. Após 3 dias realizava-se a retirada dos músculos e demais tecidos, seguida da limpeza com detergente neutro das peças ósseas. Posteriormente, o esqueleto era montado com cola instantânea (Super Bonder ${ }^{R}$ Loctite), observando-se as estruturas ósseas malformadas. $\mathrm{O}$ mesmo procedimento de maceração foi realizado com dois cordeiros, sem malformações, que foram utilizados como controle.

\section{RESULTADOS}

Durante o período estudado foram realizadas 90 necropsias. Nos diferentes quadros constam: a distribuição dos diagnósticos (Quadro 1), a distribuição das mortes, de acordo com o período no qual ocorreram (Quadro 2), o número de necropsias realizadas em cada fazenda, o município onde se localizavam as

Quadro 3. Mortalidade perinatal de ovinos. Localização das fazendas por município e raça dos ovinos necropsiados nos anos de 2002 e 2004 no semi-árido paraibano

\begin{tabular}{rlcl}
\hline Fazenda & \multicolumn{1}{c}{ Município } & $\begin{array}{c}\text { № de ne- } \\
\text { cropsias }\end{array}$ & \multicolumn{1}{c}{ Raça } \\
\hline 1 & Campina Grande & 1 & Dorper \\
2 & Condado & 1 & Santa Inês \\
3 & Patos & 2 & SRD , Santa Inês \\
4 & Patos & 1 & SRD \\
5 & Patos & 5 & SRD, Santa Inês \\
6 & Patos & 1 & SRD \\
7 & Patos & 2 & Santa Inês \\
8 & Patos & 1 & SRD \\
9 & Patos & 1 & Santa Inês \\
10 & Quixaba & 1 & SRD \\
11 & Quixaba & 3 & Santa Inês \\
12 & Santa Luzia & 2 & Santa Inês \\
13 & Santa Terezinha & 2 & SRD \\
14 & Santa Terezinha & 1 & Santa Inês \\
15 & S. José de Espinharas & 3 & Dorper, SRD \\
16 & S. José do Bonfim & 2 & SRD \\
17 & São Mamede & 3 & Somalis, Santa Inês, Cariri \\
18 & São Mamede & 6 & Santa Inês, SRD \\
19 & São Mamede & 1 & SRD \\
20 & São Mamede & 20 & SRD, Santa Inês \\
21 & São Mamede & 5 & SRD, Santa Inês \\
22 & São Mamede & 2 & Santa Inês \\
23 & São Mamede & 4 & SRD \\
24 & São Mamede & 4 & Santa Inês \\
25 & São Mamede & 2 & SRD, Santa Inês \\
26 & Soledade & 13 & Cariri, Dorper, Sta Inês, Dâmara \\
27 & Várzea & 1 & Rabo Largo \\
\hline SRD & animais sem raça definida. & \\
& & &
\end{tabular}


Quadro 4. Causas de infecção neonatal em 37 cordeiros necropsiados nos anos de 2002 e 2004 no semi-árido paraibano

\begin{tabular}{lcc}
\hline $\begin{array}{l}\text { Causa das mortes por } \\
\text { infecção neonatal }\end{array}$ & Número & $\%$ \\
\hline Broncopneumonia & 14 & 37,9 \\
Cistite & 1 & 2,7 \\
Colibacilose & 1 & 2,7 \\
Enterite & 3 & 8,1 \\
Onfalite & 6 & 16,2 \\
Onfaloartrite & 1 & 2,7 \\
Pericardite e pneumonia & 1 & 2,7 \\
Pericardite fibrinosa & 1 & 2,7 \\
Pericardite e valvulite & 2 & 5,4 \\
Poliartrite & 3 & 8,1 \\
Uraquite & 1 & 2,7 \\
Outras ${ }^{\text {a }}$ & 3 & 8,1 \\
Total & 37 & 100
\end{tabular}

a Casos que macroscopicamente apresentavam lesões sugestivas de infecção (hidrotórax, edema de pulmão, hidropericárdio, petéquias nas serosas peritonite, hepatomegalia, ascite) e na histologia apresentavam lesões inflamatórias em um ou mais órgãos. houve crescimento ou cresceram diversas bactérias aparentemente contaminantes.

Como pode ser observado no Quadro 5, as malformações mais frequientes foram a flexão dos membros anteriores, micrognatia (Fig.1, 2 e 6), fenda palatina primária (lábio leporino) (Fig.1 e 2), fenda palatina secundária (palatosquise) (Fig.3 e 4) e hipoplasia ou aplasia bilateral ou unilateral do osso incisivo (Fig.1, 2 e 5). Os cordeiros com flexão dos membros apresentavam também falta de desenvolvimento (hipoplasia) dos músculos dos membros flexionados (Fig.6). Os cordeiros com aplasia unilateral do osso incisivo apresentavam ausência de parte do lábio e palato duro e parte inferior do orifício nasal do mesmo lado (queilosquise, lábio leporino ou fenda palatina primária) (Fig.2 e Fig.5-centro). Os animais com hipoplasia unilateral do osso incisivo, que muitas vezes consistia na ausência do processo nasal desse osso, apresentavam somente fenda labial consistindo na falta de parte do lábio (Fig 1). Nos casos de aplasia havia desvio lateral do septo nasal; em consequiência, não havia oclusão dos dentes incisivos com o maxilar. Nesses casos o osso nasal apresentava-se diminuído. Nos animais com aplasia ou hipoplasia

Quadro 5. Malformações encontradas em 21 cordeiros necropsiados nos anos de 2002 e 2004 no semi-árido paraibano

\begin{tabular}{|c|c|c|c|c|c|c|c|c|c|c|c|c|c|c|c|c|c|c|c|c|c|}
\hline \multirow[t]{2}{*}{ Malformação observada } & \multicolumn{20}{|c|}{ Cordeiro no. } & \multirow[b]{2}{*}{ Total } \\
\hline & 1 & 2 & 3 & 4 & 5 & 6 & 7 & 8 & 9 & 10 & 11 & 12 & 13 & 14 & 15 & 16 & 17 & 18 & 20 & 21 & \\
\hline Acefalia & & & & & & & & & & & & & & & & & & & $\mathrm{x}$ & & 1 \\
\hline Anoftalmia unilateral & & & $\mathrm{x}$ & & & & & & & & & & & & & $\mathrm{x}$ & & & & & 2 \\
\hline Aplasia bilateral do osso incisivo & & & & & & $\mathrm{x}$ & $\mathrm{x}$ & $\mathrm{x}$ & & & $\mathrm{x}$ & & & & $\mathrm{x}$ & $\mathrm{x}$ & & & & & 6 \\
\hline Aplasia ou hipoplasia unilateral do osso incisiv & & & $\mathrm{x}$ & $\mathrm{x}$ & $\mathrm{x}$ & & & & & $\mathrm{x}$ & & $\mathrm{x}$ & & & & & $\mathrm{x}$ & $\mathrm{x}$ & & & 8 \\
\hline Bicefalia & & & & & & & & & & & & & & & & & & & & $\mathrm{x}$ & 1 \\
\hline Cifose & & $\mathrm{x}$ & & & & & & & & & & & & & & & & & & & 1 \\
\hline Escoliose & $\mathrm{x}$ & & $\mathrm{x}$ & & & & & & & & & $\mathrm{x}$ & $\mathrm{x}$ & $\mathrm{x}$ & & & & & & & 5 \\
\hline Flexão da articulação carpo-metacarpiana & $\mathrm{x}$ & $\mathrm{x}$ & $\mathrm{x}$ & $\mathrm{x}$ & $\mathrm{x}$ & & & $\mathrm{x}$ & $\mathrm{x}$ & & & $\mathrm{x}$ & $\mathrm{x}$ & $\mathrm{x}$ & & $\mathrm{x}$ & $\mathrm{x}$ & $\mathrm{x}$ & & & 13 \\
\hline Hidranencafelia & & & $\mathrm{x}$ & & & & & & & & & & & & & $\mathrm{x}$ & & & & & 2 \\
\hline Hiperlordose & & & & & & & & & & & & & & & & $\mathrm{x}$ & & & & & 1 \\
\hline Hipoplasia da língua & $\mathrm{x}$ & & $\mathrm{x}$ & & $\mathrm{x}$ & & & & & & & & $\mathrm{x}$ & $\mathrm{x}$ & & $\mathrm{x}$ & & & & & 6 \\
\hline Meningocele & & & $\mathrm{x}$ & & & & & & & & & & & & & & & & & & 1 \\
\hline Micrognatia & $\mathrm{x}$ & & $\mathrm{x}$ & & $\mathrm{x}$ & $\mathrm{x}$ & & & $\mathrm{x}$ & $\mathrm{x}$ & $\mathrm{x}$ & $\mathrm{x}$ & $\mathrm{x}$ & $\mathrm{x}$ & & $\mathrm{x}$ & $\mathrm{x}$ & $\mathrm{x}$ & & & 11 \\
\hline Palatosquise & $\mathrm{x}$ & $\mathrm{x}$ & $\mathrm{x}$ & & & $\mathrm{x}$ & $\mathrm{x}$ & & & $\mathrm{x}$ & & & & & $\mathrm{x}$ & $\mathrm{x}$ & $\mathrm{x}$ & & & & 9 \\
\hline Siringocele & & & & & & & & & & & & & & & & & & & & $\mathrm{x}$ & 1 \\
\hline Torcicolo & $\mathrm{x}$ & & $\mathrm{x}$ & & & & & & & & & $\mathrm{x}$ & $\mathrm{x}$ & $\mathrm{x}$ & & & & & & & 5 \\
\hline Total & 7 & 3 & 10 & 2 & 4 & 3 & 2 & 2 & 2 & 3 & 2 & 5 & 5 & 5 & 2 & 8 & 4 & 3 & 1 & 2 & 75 \\
\hline
\end{tabular}

mesmas e a raça dos cordeiros necropsiados (Quadro 3), a frequiência das diferentes causas de infecção neonatal (Quadro 4) e as malformações encontradas e a freqüiência das mesmas, onde o número das malformações é superior ao dos cordeiros por que todos os animais tinham mais de uma malformação (Quadro 5).

Todos os cordeiros apresentaram a gordura perirenal, pericárdica e de outras regiões da cavidade abdominal e torácica de cor branca e consistência firme, havendo somente variações na quantidade de gordura: os cordeiros menores apresentavam menor quantidade de gordura que os maiores. Em nenhum dos cordeiros necropsiados foi observada a metabolização da gordura caracterizada pela presença de gordura avermelhada e de aspecto gelatinoso.

Nas culturas bacteriológicas foi isolada Escherichia coli em cultura pura em um caso. Nos demais materiais semeados não bilateral do osso incisivo (Fig.2 e 5-esquerda) as lesões eram semelhantes, mas não havia desvio do septo nasal. Nos casos de lesões unilaterais, os demais ossos da fase e base do crânio apresentavam-se assimétricos. Alguns animais apresentavam diversas malformações, tanto da face quando dos membros (Fig.6, 7, 8 e 9$)$.

\section{DISCUSSÃO}

Os resultados desse estudo demonstram que as principais causas de morte de cordeiros no período perinatal são as infecções neonatais ( $41,1 \%$ das mortes), seguidas das malformações $(23,3 \%)$, distocias $(10 \%)$, complexo inanição/hipotermia $(10 \%)$, aborto $(4,4 \%)$ e predação $(2,2 \%)$. A infecção neonatal ocorre, aparentemente, devido a três causas: ingestão inadequada de colostro, falta de desinfecção do umbigo após o parto, e condições deficientes de higiene que são mais freqüientes em criações intensivas. 

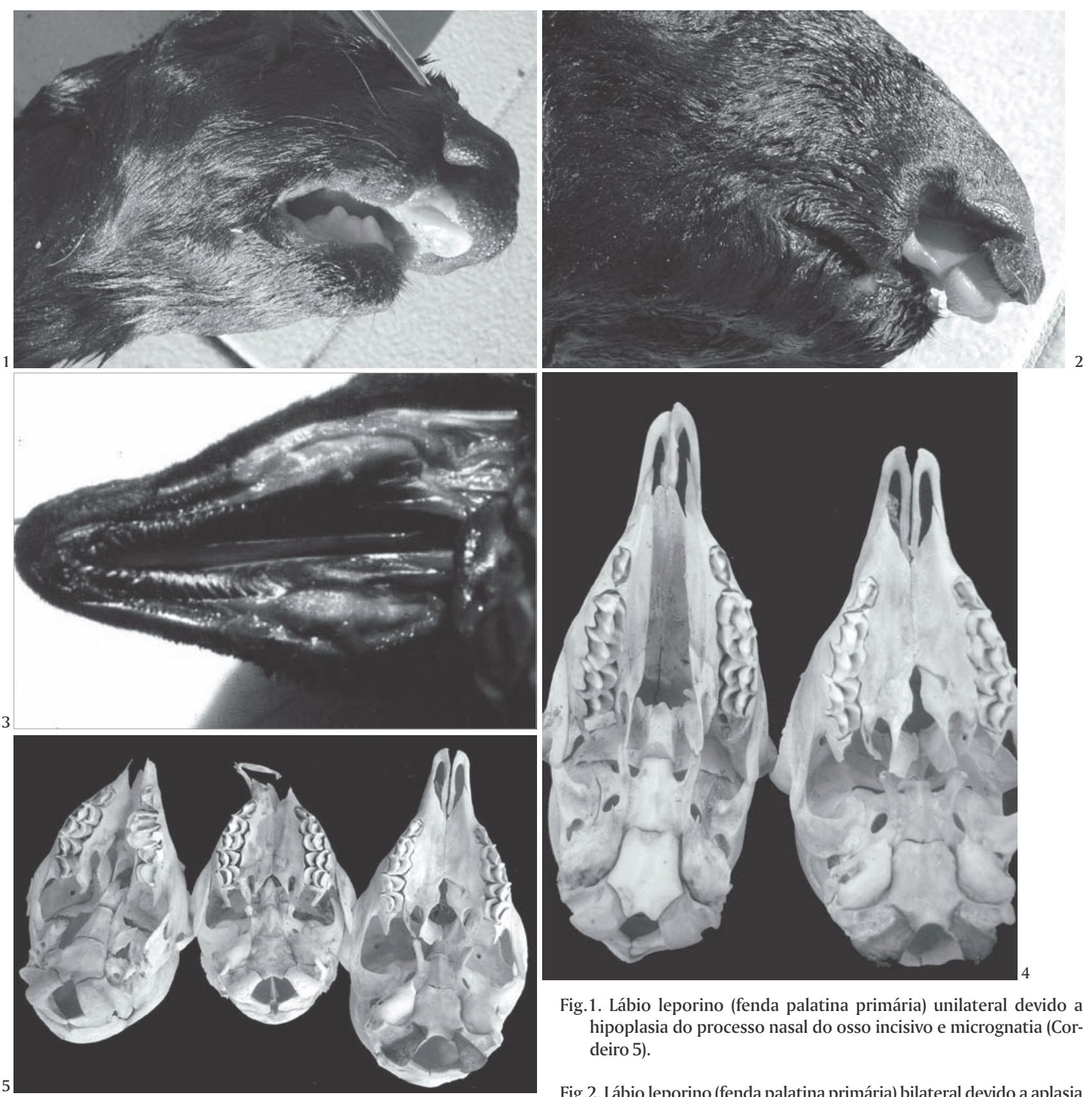

Fig.1. Lábio leporino (fenda palatina primária) unilateral devido a hipoplasia do processo nasal do osso incisivo e micrognatia (Cordeiro 5).

Devemos considerar que na região semi-árida os ovinos são criados, preferentemente, em regime extensivo, com taxas de lotação de 1,5-2 ha/ovino/ano (Araújo Filho 1992); no entanto, na maioria das fazendas, os ovinos e caprinos são presos à noite em instalações com alta concentração de animais, o que favorece a ocorrência das infecções neonatais. As principais causas de infecção neonatal podem ser controladas aumentando o atendimento durante e após o parto, procedendo à desinfecção do umbigo, administrando colostro nas primeiras 2-6 horas após o nascimento e colocando as matrizes em melhores condições ambientais, separando-as do resto do rebanho para parir.

Fig.2. Lábio leporino (fenda palatina primária) bilateral devido a aplasia bilateral de osso incisivo e micrognatia (Cordeiro 11).

Fig.3. Fenda palatina secundária, palatosquise (Cordeiro 2) .

Fig.4. Crânio do cordeiro da Fig.3 após a maceração (à esquerda) junto a crânio de cordeiro normal (à direita). Observa-se hipoplasia da maxila, ocorrendo comunicação da cavidade oral com a cavidade nasal. (Cordeiro 2)

Fig.5. O crânio macerado do Cordeiro 8 (esquerda) apresenta aplasia bilateral do osso incisivo, e o do Cordeiro 4 (no meio), aplasia unilateral do osso incisivo. Testemunha a direita. 


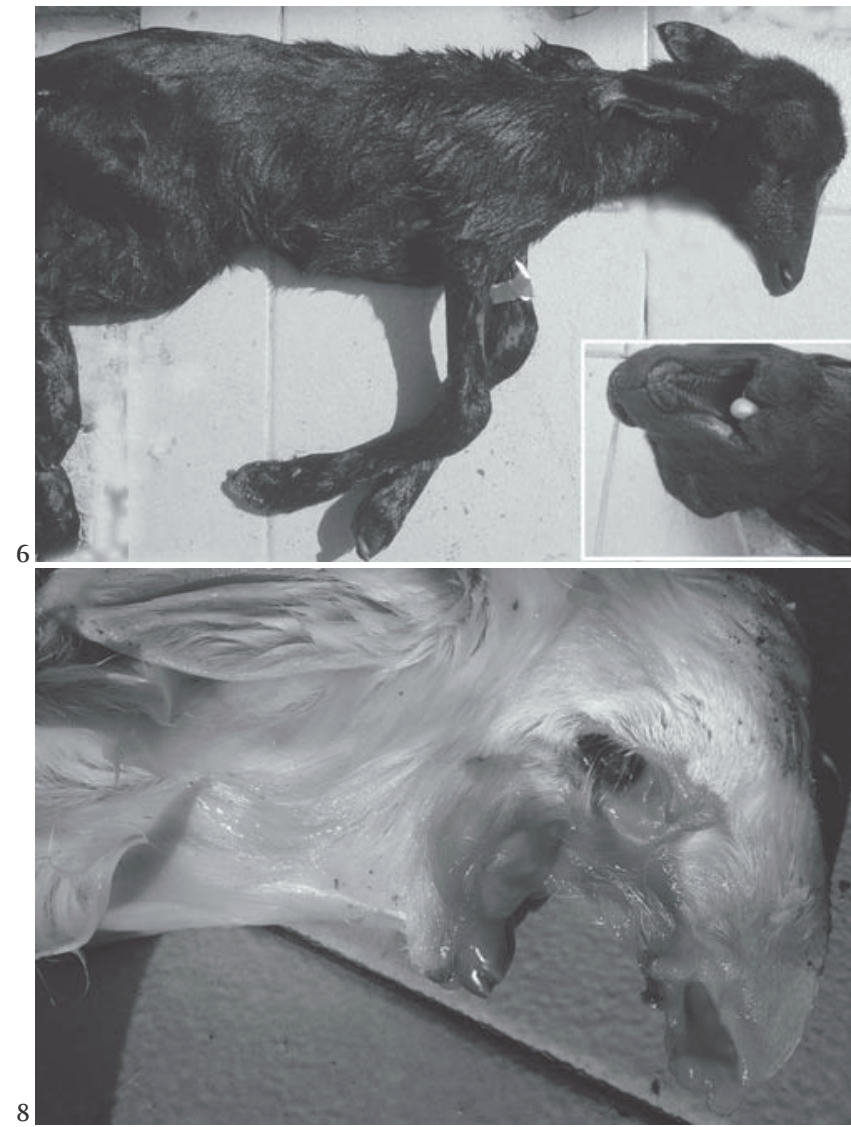

Fig.6. Flexão dos membros anteriores, com hipoplasia muscular e severa micrognatia (Cordeiro 9).

Fig.8. Diversas malformações da cabeça do Cordeiro 6: micrognatia, aplasia bilateral do osso incisivo, palatosquise e malformação da órbita.

Neste trabalho as malformações foram a segunda causa mais freqüente de mortalidade perinatal. A alta freqüência de malformações, em diferentes tipos de criação e em diferentes raças, sugere que essas malformações são de origem tóxica. Pimentel \& Riet-Correa (2004, dados não publicados) reproduziram malformações do osso palatino, entre outras, em cabritos filhos de cabras alimentadas durante toda a gestação com Mimosa tenuiflora ("jurema-preta"), demonstrando o efeito teratogênico dessa planta que é, provavelmente, a causa da maioria das malformações encontradas neste trabalho. Para diminuir a freqüência dessas malformações é necessário evitar a ingestão de jurema-preta por ovelhas prenhes, principalmente nos primeiros 60 dias de gestação, período durante o qual o feto é mais susceptível aos agentes teratogênicos.

O complexo inanição/hipotermia e as distocias foram as outras causas mais importantes de morte depois das infecções neonatais e malformações. Esses resultados diferem de resultados encontrados no Rio Grande do Sul, onde, em diferentes anos, o complexo inanição/hipotermia foi a causa mais importante de mortalidade, variando de $56 \%$ a $78 \%$ (Méndez et al.
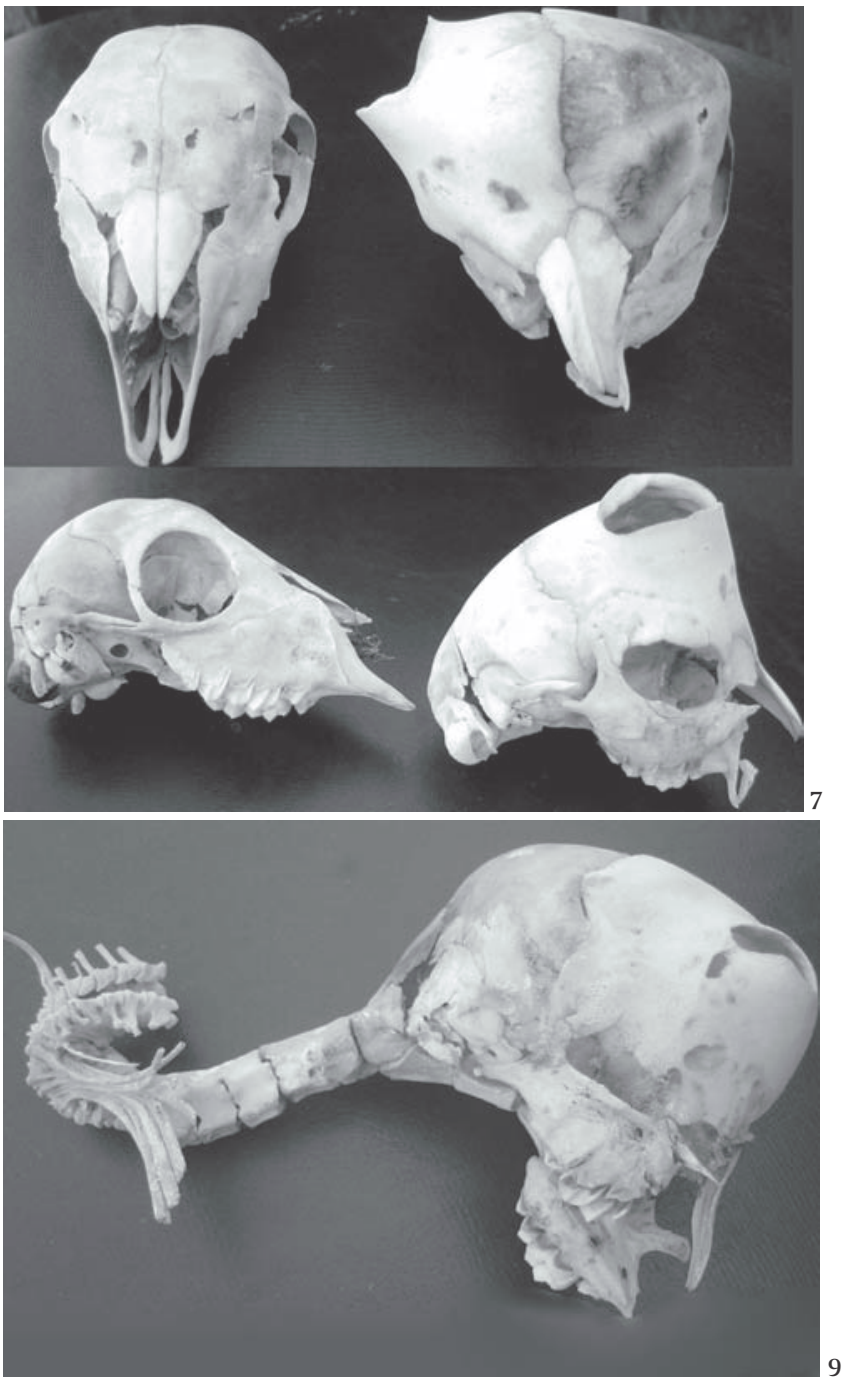

Fig.7. Crânio macerado do Cordeiro 3 (direita) junto ao crânio de um cordeiro testemunha (esquerda) em visão frontal (em cima) e lateral (em baixo). Observam-se diversas alterações dos ossos do crânio, incluindo falha no fechamento do osso frontal (meningocele), malformação da órbita, aplasia unilateral do osso incisivo direito com permanência do osso incisivo esquerdo apresentando desvio lateral. Há evidente assimetria dos ossos nasais e outros ossos.

Fig.9. Crânio e parte da coluna vertebral macerados do Cordeiro 16, com palatosquise, aplasia bilateral do osso incisivo, hiperlordose, meningocele, anoftalmia e severa micrognatia (a mandíbula formada por ossos muito pequenos não foi montada no crânio).

1982, Oliveira \& Barros 1982, Hancock et al. 1996). Em outros países de clima temperado com criação extensiva de ovinos a causa mais freqüente de morte é, também, o complexo inanição/hipotermia (Dennis 1974, Mari \& McCosker 1975, Yapi et al. 1990, Green \& Morgan 1993). Essa situação ocorre, também, em alguns países com regiões semi-áridas como no Marrocos (Chaarani et al. 1991) e na Etiópia (Bekele et al. 1992). 
O complexo inanição/hipotermia ocorre principalmente por dois fatores: o baixo peso ao nascimento e as condições ambientais adversas. Estas últimas são muito importantes em países de clima temperado onde os cordeiros nascem em épocas frias e chuvosas (Riet-Correa \& Méndez 2001). No semiárido onde as condições climáticas são mais favoráveis para a sobrevivência dos cordeiros, a causa mais importante de inanição/hipotermia é o baixo peso ao nascimento, em consequiência de níveis nutricionais inadequados das matrizes durante o último terço de gestação. Doenças das ovelhas como foot-rot e parasitoses podem, também, interferir no crescimento do feto. A importância da nutrição na sobrevivência do cordeiro é sugerida pelo fato de que os cordeiros com menor peso ao nascimento são os que apresentam maior taxa de mortalidade por inanição/hipotermia (Quadro 1). O abandono dos cordeiros por parte das mães e alterações do úbere podem, também, influir na sobrevivência do cordeiro. Uma melhor nutrição das mães é a principal forma de prevenir as mortes por esta causa.

Um fato que chama atenção é o de não ter sido observado em nenhum cordeiro necropsiado, principalmente nos mortos por inanição/hipotermia, a metabolização da gordura, caracterizada por apresentar um aspecto gelatinoso de cor avermelhada, diferente da gordura normal, de cor branca e consistência firme (McFarlane 1961, Haughey 1973, Méndez et al. 1982). É provável que essa não-metabolização da gordura esteja associada à temperatura ambiente. Os países, nos quais essa alteração é descrita, são de clima temperado, com temperaturas bem inferiores às observadas no semi-árido. A gordura do recém nascido, quase que totalmente formada por gordura marrom, é utilizada para a termogênese não associada ao tremor e, experimentalmente, a sua metabolização ocorre a temperaturas de $0-18^{\circ} \mathrm{C}$ e não a temperaturas de $20-35^{\circ} \mathrm{C}$, tanto em cordeiros alimentados, quanto em cordeiros com fome (Haughey 1973). Os resultados deste trabalho mostram que às temperaturas do semi-árido essa gordura não é metabolizada para a produção de calor. Isso sugere que nos cordeiros que morrem por hipotermia a mesma ocorre em conseqüência da hipoglicemia, por falta de alimento e não por perda de calor. Outra diferença que poderia influir na não mobilização da gordura é a diferença racial; enquanto nos países de clima temperado são utilizadas raças lanadas, no semi-árido são utilizadas raças deslanadas.

0 percentual de mortes por distocias é semelhante aos observados em outros trabalhos do Brasil que varia de $8,6 \%$ a $16,7 \%$ (Méndez et al 1982, Oliveira \& Barros 1982, Hancock et al. 1996, Montenegro et al. 1998). O atendimento durante o parto é a principal forma de diminuir a mortalidade por distocias.

Neste trabalho, os abortos não foram causa importante de perdas no período perinatal nas fazendas estudadas. Apesar disso, surtos de abortos são freqüentes no semi-árido da Paraíba e numerosas plantas são incriminadas como causa de abortos em ovinos e caprinos. Trabalhos recentes demonstraram o efeito abortivo de Aspidosperma pyrifolium ("pereiro") em caprinos. A ingestão desta planta é uma causa importante de abortos, principalmente em épocas de seca, quando após uma chuva o pereiro rebrota rapidamente e é consumido pelos ovinos e caprinos (Medeiros et al. 2004).
A predação não foi uma causa importante de morte neonatal. Apesar disso, numerosos produtores incriminam algumas aves como o carcará (Polyborus plancus) e o urubu (Catharte spp), a raposa (Dusicyon vetulus), o gato-maracajá (Leopardus tigrinus) e o gatojaguarandi-vermelho (Felis yagouaroundi) como predadores primários. É necessário, no entanto, comprovar esses fatos antes de recomendar qualquer medida de controle para esses possíveis predadores silvestres. Devemos considerar que, historicamente, as tentativas de reduzir perdas perinatais de ovinos têm-se concentrado em programas de controle de predadores (Gluesing et al. 1980), isto por que os produtores assumem que a principal causa de morte é a predação. Em algumas zonas do Uruguai se atribui grande parte da mortalidade de cordeiros ao ataque de animais predadores (aves de rapina e raposas, principalmente), no entanto tanto raposas como aves de rapina em poucos casos matam cordeiros sadios; mas sim se aproveitam dos cordeiros próximos a morrer por outras causas (Azzarini \& Ponzoni 1971).

Quando analisamos o momento de morte dos cordeiros (Quadro 2), observamos que o número de cordeiros mortos após os 3 dias de vida $(35,56 \%)$ foi maior que os mortos durante as primeiras 24 horas (30\%) e do que os mortos entre o primeiro e terceiro dia de vida $(20 \%)$. Esses resultados são diferentes dos obtidos em países de clima temperado, onde a grande maioria dos cordeiros morre nos primeiros 3 dias de vida, em conseqüência de inanição/hipotermia (Moule 1954, Safford \& Hoversland 1960, Mari \& McCosker 1975, Laborie 1980, Méndez et al. 1982, Oliveira \& Barros 1982). Essa diferença deve-se ao fato que no semi-árido as principais causas de morte são as infecções neonatais, que podem ocorrer vários dias após o nascimento, enquanto que nas regiões temperadas a principal causa de morte é a inanição/hipotermia. Em conseqüência disso, na região semi-árida o cuidado com os cordeiros deve-se estender até, pelo menos, os 28 dias, enquanto nas regiões temperadas o período mais importante são os três primeiros dias de vida.

Atualmente, na região nordeste, na grande maioria das fazendas, os carneiros permanecem com as ovelhas durante todo o ano. Considerando esse fato, além das medidas mencionadas anteriormente para diminuir as perdas ocasionadas pelas diferentes causas, a maioria de baixo custo, é necessário estabelecer uma época de estação de monta, fazendo coincidir a época de maior necessidade nutricional das ovelhas com a maior disponibilidade de forragem e/ou suplementos. Para isso, são necessárias pesquisas, tanto na produção de forragem durante a época de chuvas, quanto na suplementação com concentrados, feno ou silagem durante a seca, que indiquem a época de acasalamento mais adequada do ponto de vista econômico e da produção. Um fato que chamou a atenção durante o desenvolvimento deste trabalho foi a dificuldade em obter dados por parte dos produtores e tratadores sobre aspectos produtivos dos rebanhos, incluindo taxas de nascimento, mortalidade e desmame. A determinação de uma época de acasalamento e a adoção de um método de coleta de dados (escrituração zootécnica) permitiria um melhor planejamento das atividades das fazendas, assim como a deteç̧ão de outros problemas limitantes da produção.

Agradecimentos.- Projeto financiado pelo Conselho Nacional de Desenvolvimento Científico e Tecnológico (CNPq, Processo 470964/2003-0). 


\section{REFERÊNCIAS}

Araújo Filho J.A. 1992. Manipulação da vegetação lenhosa da caatinga para fins pastoris. Circular Técnico s/n, Embrapa-CNPC, Sobral, Ceará. $18 \mathrm{p}$.

Azzarini M. \& Ponzoni R. 1971. Aspectos modernos de la producion ovina. Departemento de Publicaciones, Universidade de la República, Montevideo. 197p.

Bekele T., Kasali O.B., \& Woldeab T. 1992. Causes of lamb morbidity and mortality in the Ethiopian highlands. Vet. Res. Commun.16(6):415-424.

Chaarani B., Robinson R.A. \& Johnson D.W. 1991. Lamb mortality in Meknes province (Morocco). Prev. Vet. Med. 10:283-298.

Dennis S.M. 1974. Perinatal lamb mortality in western Australia. Aust. Vet. J. 50:443-449.

Green L.E. \& Morgan K.L. 1993. Mortality in early born, housed lambs in south-west England. Prev. Vet. Med. 17: 251-261.

Girão R.N., Medeiros L.P. \& Girão E.S. 1998. Mortalidade de cordeiros da raça Santa Inês em um núcleo de melhoramento no estado do Piauí Ciência Rural, Santa Maria, 28(4):641-645.

Gluesing E.A.; Balph D.F. \& Knowlton F.F. 1980. Behavioral patterns of domestic sheep and their relationship to coyote predation. Appl. Anim. Ethology (6):315-330.

Hartley W.J. \& Boyes B.W. 1964. Incidence of ovine perinatal mortalty in New Zealand with particular reference to intrauterine infections. N. Z Vet. J. 12:33-36.

Haughey K.G. 1973. Cold injury in newborn lambs. Aust. Vet. J. 49:554 563.

Hancock R.D., Coe A.J. \& Silva F.C. 1996. Perinatal mortality in lambs in southern Brazil. Trop. Anim. Health Prod. 28(4):266-72.

Laborie C.H.C. 1980. Motalidad perinatal en corderos bajo régimen de parición controlada. Anais $2^{a}$ Reunión sobre Investigación em Producción de la Zona Sur, Uruguaiana, p.5-6.

Lima F.A.M. 1985. Desempenho dos ovinos deslanados no Nordeste brasileiro e planos de melhoramento para o futuro. Anais Simpósio Int. Prod. Animal 1983. Sociedade Brasileira de Genética, Ribeirão Preto, p.45-65.

Lobo R.N.B. 2002. Melhoramento genético de caprinos e ovinos: desafios para o mercado. Anais VI Seminário Nordestino de Pecuária, Fortaleza, FAEC IV, p.44-60.

Mari J.J. \& McCosker P.J. 1975. Consideraciones sobre mortandad perinatal en ovinos en el Uruguay. VI Encuentro Veterinario Internacional, Punta del Eeste, Uruguay, p.1-2.

McFarlane D. 1965. Perinatal lamb losses. An autopsy method for the investigation of perinatal losses. N. Z. Vet. J. 13:116-135.

Medeiros R.M.T., Neto S.A., Riet-Correa F., Schild A.L. \& Sousa N.L. 2004. Mortalidade embrionária em caprinos causados por Aspidosperma pyrifolium. Pesq. Vet. Bras. 24 (Supl.):42-43. (Resumo)

Méndez M.C., Riet-Correa F., Ribeiro J., Selaive A. \& Schild A.L. 1982. Mortalidade perinatal em ovinos nos municípios de Bagé, Pelotas e Santa Vitória do Palmar, Rio Grande do Sul. Pesq. Vet. Bras. 2(2):6976.

Moule G,R. 1954. Observations on mortality amongst lambs in Queensland. Aust. Vet. J. 30:153-171.

Montenegro M.L., Siqueira R.E., Rocha, N.S. \& Peres, J.A. 1998. Mortalidade de cordeiros em duas propriedades na região de Botucatu, São Paulo. Anais XXV Reunião Anual da Sociedade Brasileira de Zootecnia, Botucatu, p.1-4.

Oliveira A.C. \& Barros S.S. 1982. Mortalidade perinatal em ovinos no município de Uruguaiana, Rio Grande do Sul. Pesq. Vet. Bras 2(1):1-7.

Radostits O.M., Gay C.C., Blood D.C. \& Hinchcliff K.W. 2000. Veterinary Medicine. 9th ed. W.B. Saunders, London, p.104-136.

Riet-Correa F. \& Méndez M.C. 2001. Mortalidade perinatal em ovinos, p.417-425. In: Riet-Correa F., Schild A.L., Méndez M.C. \& Lemos R.A.A. (ed.) Doenças de Ruminantes e Eqüinos. $2^{\underline{a}}$ ed. Livraria Varela, São Paulo.

Safford J.W \& Hoversland A.S. 1960. A study of lamb mortality in a western range flock. I. Autopsy findings on 1051 lambs. J. Anim. Sci. 19:256-272.

Stamp J.T. 1967. Perinatal lamb loss in lambs with particular reference to diagnosis. Vet. Rec. 81:530-536

Turkson P.K. 2003. Lamb and kid mortality in village flocks in the coastal savanna zone of Ghana. Trop. Anim. Health Prod. 35(6):477-490.

Yapi C.V., Boylan W.J. \& Robinson R.A. 1990. Factors associated with causes of preweaning lamb mortality. Prev. Vet. Med. 10:145-152. 